SESSION III

TREATMENT OF ASCITES

\author{
Chairman: Professor Sheila Sherlock
}

\title{
A rational approach to the treatment of ascites
}

\author{
V. ARroyo \\ M.D. \\ J. RODÉS \\ M.D.
}

The Liver Unit, Hospital Clínico y Provincial, University of Barcelona, Spain

\section{Summary}

A rational approach to the diuretic therapy of ascites is proposed. Fifty-five patients were classified according to their ability to excrete sodium and free water. Patients with a high urinary sodium excretion can be treated by low sodium intake alone. In most patients with a low sodium excretion but high free water clearance, distal diuretics (spironolactone or triamterene) with a low sodium diet will relieve ascites. Patients with low values for sodium excretion and free water clearance also have poor glomerular filtration rate and only a few of these will respond to diuretic therapy.

THE oldest known form of therapy of ascites is paracentesis which was extensively used from the Graeco-Roman period until very recently (Dawson, 1960). There is evidence that paracentesis can be dangerous since it may induce protein and sodium depletion and hyponatraemia, functional renal failure and circulatory shock (Nelson, Rosenbaum and Strauss, 1951 ; Papper, Belsky and Bleifer, 1959).

At present, the main problem in the approach to the therapy of ascites is that its pathophysiology is uncertain (Conn, 1972). Nevertheless, it seems clear that patients with cirrhosis and ascites must be considered as having two principal disorders which may or may not be related. Firstly, they have disorders which can induce exudation of fluid into the peritoneal cavity, namely portal hypertension, hypoalbuminaemia and an increased hepatic lymph production. The second important disorder is the presence of a renal dysfunction (Baldus et al., 1964; Shear, Hall and Gabuzda, 1965), characterized in all the patients by an increased renal tubular sodium resorption. Some patients also have a decreased glomerular filtration rate and an impaired ability to excrete free water (Baldus et al., 1964; Shear et al., 1965).

\section{Pathophysiology of ascites}

Portal hypertension and hypoalbuminaemia wers $\vec{\theta}$ initially considered the chief factors in the pathe of physiology of ascites (Atkinson and Losowsk 1962). Either factor, by breaking the Starling equil brium, could induce exudation of fluid from the peritoneum into the abdominal cavity. Subsequently it was suggested that post-sinusoidal portal hypertension could also induce the formation of ascites by increasing hepatic lymph production (Dumont and Mulholland, 1965). Ascites would be produced by exudation of lymph from the liver surface when the hepatic lymph production was greater than the drainage capacity of the lymphatic system of the liver and of the thoracic duct.

According to this theory the renal dysfunction would be a response to a decrease of 'effective' plasma volume resulting from ascites formation and from sequestration of blood into the portal venous system (Eisenmenger, 1952; Papper, 1958).

However, there are some data against this hypo- $\frac{7}{0}$ thesis. Many patients with cirrhosis and portal hypertension and/or hypoalbuminaemia do not have $N$ ascites. Plasma volume is high in the majority of the patients with cirrhosis and ascites (Lieberman and $N$ Reynolds, 1967) and the expansion of plasma volume $\omega$ does not produce appreciable or lasting improvement of renal function (Lieberman, Ito and Reynolds, 1969).

This theory of ascites has been the basis for some form of treatment. The relief of the portal hypertension by portacaval anastomosis has been useful in some patients (Schroeder, Numann and Chamber- 
lain, 1970). However, this type of surgery has a high mortality (Welch, Welch and Carter, 1964). The external canulation of the thoracic duct and the drainage of large amounts of lymph are not a practical form of therapy and some authors consider that this procedure is a difficult way of performing a paracentesis (Orloff et al., 1966). The expansion of plasma volume by plasma, albumin or ascitic fluid infusions only produces transitory increases of diuresis and natriuresis and can induce complications, mainly gastrointestinal bleeding (McCloy et al., 1967).

Recently, Lieberman, Denison and Reynolds (1970) have proposed an alternative hypothesis which considers that ascites formation in cirrhosis is a consequence of the plasma-expanding effect of renal sodium retention (Denison, Lieberman and Reynolds, 1971). This theory suggests that the initial disorder in ascites is the renal dysfunction, and that portal hypertension is only a factor which localizes the oedema.

Whichever may be the pathophysiology of ascites, most clinicians agree that the correction of the increased renal sodium retention by using diuretics is, at the moment, the best therapy of this condition. This therapy, although it can induce complications such as serum-electrolyte disturbances, prerenal azotaemia, and hepatic coma (Sherlock et al., 1966), is effective in approximately $80 \%$ of cases.

\section{Therapeutic and prognostic implications of renal func- tion in cirrhosis}

Although the mechanism which induces renal dysfunction in cirrhosis is not known, there are a considerable number of studies which demonstrate that the intensity of this disorder is one of the best markers of the prognosis and of the future therapeutic response of a patient with cirrhosis and ascites (Hecker and Sherlock, 1956). At present, with our large and effective diuretic armamentarium, it is difficult to separate 'intractable ascites' from 'functional renal failure'. The majority of, if not all, the patients without these complications present a positive response to diuretic therapy.

Arroyo (1972) carried out a prospective study in our Unit in order to evaluate the prognostic and therapeutic implications of renal function in cirrhosis with ascites. In this study we proposed a classification of cirrhosis with ascites based on the renal capacity to excrete sodium and free water which may be useful for a rational treatment of ascites.

Fifty-five consecutive patients with cirrhosis and ascites were studied, after 7 days on bed rest and low salt intake (40-50 mEq/day), by determining glomerular filtration rate (GFR) using inulin clearance $\left(\mathrm{C}_{\mathrm{INU}}\right)$, renal plasma flow (RPF) using paramino- hippurate clearance $\left(\mathrm{C}_{\mathrm{PAH}}\right)$, free water clearance $\left(\mathrm{C}_{\mathrm{H}_{2} \mathrm{O}}\right)$ after an intravenous water load of $20 \mathrm{ml} /$ body wt (as $5 \%$ dextrose), plasma sodium concentration $\left(P_{\mathrm{Na}}\right)$, and urinary sodium concentration $\left(\mathrm{U}_{\mathrm{Na}}\right)$. Twenty-seven of these patients had never received diuretics. The others had not received diuretics for at least 10 days before the renal function studies. Water intake was free. Renal function studies were performed at approximately 9 a.m. on the eighth day, after overnight fasting from food, liquid and cigarettes. Patients who did not lose ascites and body weight within the first 7 days of admission were started on diuretics immediately following completion of renal function studies. Initially triamterene $(300 \mathrm{mg} /$ day $)$ or spironolactone $(150 \mathrm{mg} /$ day $)$ were given, but if a satisfactory diuresis was not obtained, frusemide (40-80 mg/day) was added. Patients who did not lose at least $2 \mathrm{~kg}$ of body weight after 15 days in spite of low salt intake, triamterene or spironolactone and frusemide, were considered to have a negative response to therapy.

Twenty-one patients were already losing ascites after 7 days of bed rest and low salt intake alone. They had a relatively high urinary sodium concentration $(82.3 \pm 57 \cdot 3 \mathrm{mEq} / \mathrm{l})$ (mean \pm s.d.) and were considered 'salt tolerant'. The other thirty-four patients who did not lose ascites on bed rest and low salt intake were considered 'salt intolerant'. They had a significantly lower urinary sodium concentration $(7 \cdot 7 \pm 8 \cdot 4 \mathrm{mEq} / \mathrm{l})$.

The criteria of classification with regard to the renal capacity to excrete free water were obtained after plotting free water clearance against plasma sodium concentration (Fig. 1). Hyponatraemia (plasma sodium concentration of less than 130 $\mathrm{mEq} / \mathrm{l}$ ) was present in thirteen of seventeen patients with a free water clearance of less than $1 \mathrm{ml} / \mathrm{min}$ and in only eight of thirty-eight with free water clearance greater than $1 \mathrm{ml} / \mathrm{min}$. This suggests that when free water clearance is less than $1 \mathrm{ml} / \mathrm{min}$ overhydration and hyponatraemia usually occur. Patients with free water clearance greater than $1 \mathrm{ml} / \mathrm{min}$ were therefore considered 'water tolerant' and those with free water clearance lower than $1 \mathrm{ml} / \mathrm{min}$ 'water intolerant'.

On the basis of these criteria there were three groups of patients (Fig. 2): group I, twenty-one patients, water and salt tolerant; group II, seventeen patients, water tolerant but salt intolerant; group III, seventeen patients, water and salt intolerant. No patient was water intolerant and salt tolerant.

Patients of groups I and II had relatively good renal function. There were no significant differences between these two groups of patients in GFR (Fig. 3) and RPF (686 $\pm 223 \mathrm{ml} / \mathrm{min}$ for group I and $552 \pm$ $152 \mathrm{ml} / \mathrm{min}$ for group II). However, patients of group III had poor renal function. They had a significantly lower GFR (Fig. 3) and RPF (363 \pm 241 


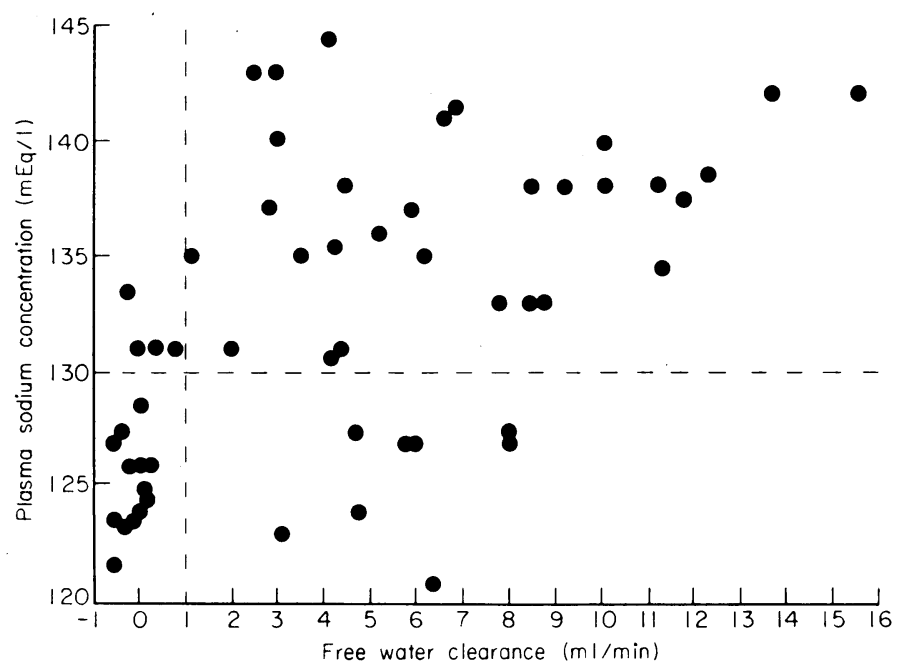

FIG. 1. Relationship between plasma sodium concentration and free water clearance.
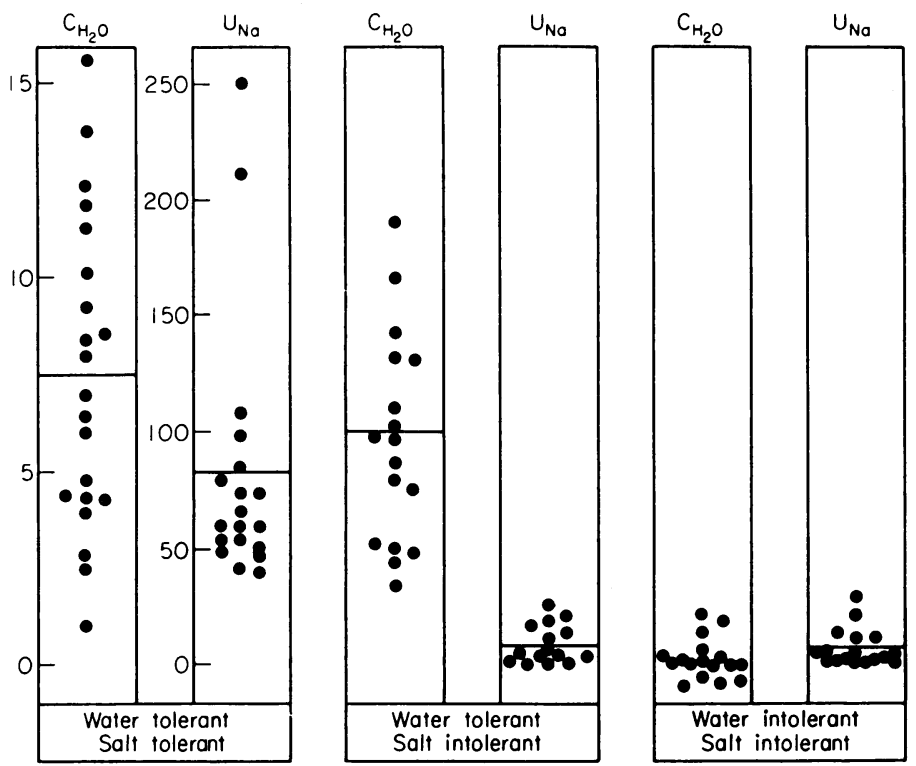

FIG. 2. Classification of the patients in relation with the renal capacity to excrete free water and sodium.

$\mathrm{ml} / \mathrm{min})$ than those in the other two groups $(P<$ 0.001).

The salt and water tolerant patients by definition lost ascites on bed rest and low salt intake alone. In eight cases distal diuretics were later given so as to accelerate discharge from hospital, and in each instance this was followed by a great increase in water and sodium excretion.

Patients of group II needed diuretics because of their low urinary sodium concentration but all of 


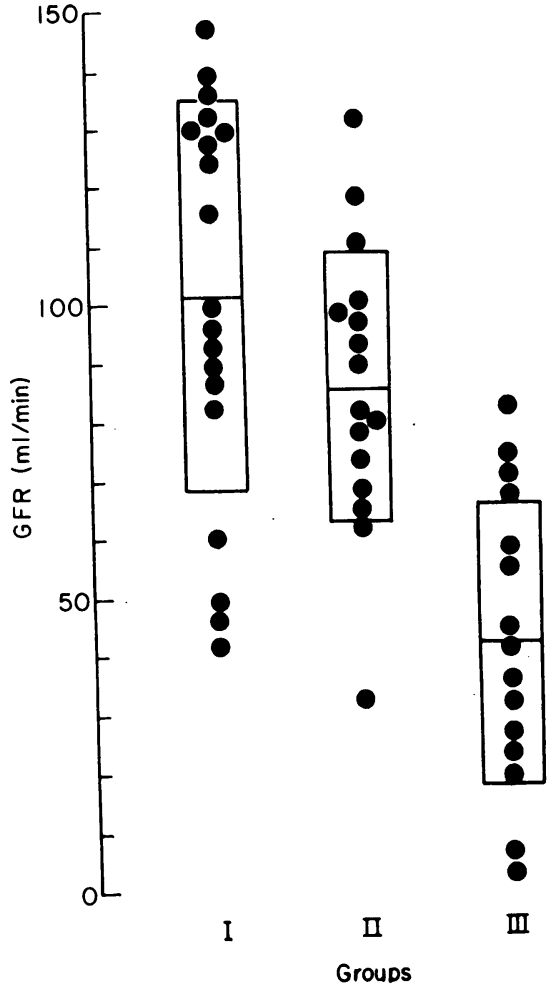

FIG. 3. Differences in glomerular filtration rate (GFR) between the three groups of patients.

nosis: all the cases were discharged from hospital without ascites. In group II, four of the seventeen patients died while in hospital. This mortality was significantly higher than in group $I(P<0.05)$. Patients of group III had a very poor prognosis: only six of seventeen survived. The mortality in this group was significantly higher than in group II $(P<0.05)$.

The determination of free water clearance can provide useful information of the renal handling of sodium. Free water is normally generated within the kidney as a result of sodium resorption from the water-impermeable ascending limb of the loop of Henle (Harrington and Cohen, 1973). The urine entering the distal tubule is then hypotonic and can remain so if antidiuretic hormone secretion is inhibited. Thus a high $\mathbf{C}_{\mathrm{H}_{2} \mathrm{O}}$ may indicate a good delivery of sodium into the distal tubule.

Patients who have been water and salt tolerant have a relatively high GFR, free water clearance and urinary sodium excretion. The reason why these patients develop ascites in spite of having a high urinary sodium concentration might be that they were salt intolerant before admission to hospital and have become salt-tolerant after bed rest. However since all the patients in our series had a relatively high urinary sodium excretion within the first day of admission, the most likely explanation is that they were ingesting more sodium than they were able to excrete while on a free salt intake before admission. This type of patient does not need water restriction since they have a sufficiently high renal capacity to excrete free water. The most rational treatment is bed rest and low salt intake and, if diuretics are given, they should be distal diuretics, since such patients respond very well to these drugs and the use of frusemide or ethacrynic acid is unnecessary and, because of the stronger natriuretic effect, may give rise to the complications frequently encountered in the course of this therapy (Sherlock et al., 1966).

The GFR and free water clearance of patients who were water tolerant/salt intolerant were not significantly different from those in the patients of group I. Therefore it is probable that similar amounts of sodium were delivered into the ascending limb of the loop of Henle and distal tubule. Thus distal sodium resorption was the critical factor in these cases, producing a urine with very low concentration of sodium. Such patients do not need water restriction, but diuretic therapy is necessary since they have a low urinary sodium excretion. However, the majority of the patients will lose ascites on distal diuretics because an enhanced distal sodium resorption is probably the most important factor in sodium retention. In our experience, approximately $90 \%$ of the water tolerant/salt intolerant patients lose their ascites on bed rest, low salt intake, and triamterene $300 \mathrm{mg} /$ day (Rodés et al., 1972). Proximal diuretics (frusemide, ethacrynic acid) should only be used in those few patients of this group who do not respond to the above-mentioned therapy. These diuretics should always be administered in association with distal diuretics since the sodium delivered from the proximal parts of the nephron could be completely resorbed in the distal tubule (Berliner, 1965).

Patients who were water and salt intolerant had a very poor GFR and free water clearance. Here it is probable that the decrease of filtered sodium and a relative increase of proximal sodium resorption were the chief factors in sodium retention. These patients do need water restriction because they have a very poor renal capacity to excrete it, and hyponatraemia and hypo-osmolality are frequent in these cases. Diuretics should also be tried because a few patients will have a positive response, but the majority will die. A wide variety of treatments has been proposed for these patients with intractable ascites. However, the results have not been encouraging and, accordingly, these treatments are not usually employed. We feel that only in this group of patients should new and aggressive forms of treatments be tried. Those of 
the other two groups have a good prognosis when treated with such simple measures as bed rest, low salt intake and diuretics.

\section{References}

ARroyo, V. (1972) Valor pronostico del funcionalismo renal en la cirrosis hepatica con ascitis. Doctoral thesis, Universidad de Barcelona.

Atkinson, M. \& Losowsky, M.S. (1962) Plasma colloid osmotic pressure in relation to the formation of ascites and oedema in liver disease. Clinical Science, 22, 383.

Baldus, W.P., Feichter, R.N., Summerskill, W.H.J. \& Hunt, J.C. (1964) The kidney in cirrhosis. II. Disorders in renal function. Annals of Internal Medicine, 60, 366.

BERLINER, R.W. (1965) Use of modern diuretics. Circulation, 33, 802 .

ConN, H.O. (1972) The rational management of ascites. In: Progress in Liver Disease (Ed. by $\mathrm{H}$. Popper and F. Schaffner), p. 269. Grune and Stratton, New York, London.

DAwson, A.D. (1960) Historical notes on ascites (Editorial). Gastroenterology, 39, 709.

Denison, E.K., Lieberman, F.L. \& ReYnolds, T.B. (1971) 9-alpha-fluorohydrocortisone induced ascites in alcoholic liver disease. Gastroenterology, 61, 497.

Dumont, A.E. \& Mulholland, J.H. (1965) Hepatic lymph in cirrhosis. In: Progress in Liver Disease (Ed. by $\mathrm{H}$. Popper and F. Shaffner), Vol. II, p. 427. Grune and Stratton, New York.

EISENMENGER, W.J. (1952) Role of sodium in the formation and control of ascites in patients with hepatic cirrhosis: A review. Gut, 37, 261.

HARRINGton, J.T. \& CohEN, J.J. (1973) Clinical disorders of urine concentration and dilution. Archives of Internal Medicine, 131, 810.

Hecker, R. \& Sherlock, S. (1956) Electrolyte and circulatory changes in terminal liver failure. Lancet, ii, 1121.

Lieberman, F.L., Denison, E.K. \& Reynolds, T.B. (1970) The relationship of plasma volume, portal hypertension, ascites and renal sodium retention in cirrhosis: The overflow theory of ascites formation. Annals of the New York Academy of Sciences, 179, 202.

Lieberman, F.L., Ito, S. \& Reynolds, T.B. (1969) Effective plasma volume in cirrhosis with ascites. Evidence that a decreased value does not account for renal sodium retention, a spontaneous reduction in glomerular filtration rate (GFR), and a fall in GFR during drug-induced diuresis. Journal of Clinical Investigation, 48, 975.

Lieberman, F.L. \& ReYNOLDS, T.B. (1967) Plasma volume in cirrhosis of the liver. Its relation of portal hypertension, ascites and renal failure. Journal of Clinical Investigation, 46, 1297.

Nelson, W.P., Rosenbaum, J.D. \& Strauss, M.B. (1951) Hyponatremia in hepatic cirrhosis following paracentesis. Journal of Clinical Investigation, 30, 738.

McCloy, R.M., Baldus, W.P., Maher, F.T. \& SummerSKILL, W.H.J. (1967) Effects of changing plasma volume, serum albumin concentration and plasma osmolality on renal function in cirrhosis. Gastroenterology, 53, 229.

Orloff, M.J., Wright, P.W., De Benedetti, M.J., Halasz, N.A., AnNets, D.L., Musicant, M.E. \& Goodhead, B. (1966) Experimental ascites. VII. The effects of external drainage of the thoracic duct on ascites and hepatic haemodynamics. Archives of Surgery, 93, 119.

PAPPER, S. (1958) The role of the kidney in Laennec's cirrhosis of the liver. Medicine, 37, 299.

PAPPer, S., Belsky, J.L. \& Bleifer, K.H. (1959) Renal failure in Laennec's cirrhosis of the liver. I. Description of clinical and laboratory features. Annals of Internal Medicine, 51, 759.

Rodés, J., Bosch, J., Arroyo, V., Nicolau, I., Teres, J. \& Bruguera, M. (1972) El triamterene en el tratamiento de la cirrosis hepatica con ascitis. Revista clínica española, 127, 1101.

Schröder, E.T., NumanN, P.J. \& Chamberlain, B.Fo (1970) Functional renal failure in cirrhosis. Recovery aftes portal-caval shunt. Annals of Internal Medicine, 72, 923.

Shear, L. Hall, W.P. \& Gabuzda, G.J. (1965) Renal failure in patients with cirrhosis of the liver. II. Factors influencin? maximal urinary flow rate. American Journal of Medicine, 39, 199.

Sherlock, S., Senewiratne, B., Scott, A. \& Walker, J.G. (1966) Complications of diuretic therapy in hepatic cirrhosis. Lancet, i, 1049.

Welch, H.F., Welch, C.S. \& Carter, J.H. (1964) Prognosis after surgical treatment of ascites. Results of side-to-side shunt in 40 patients. Surgery, 56, 75. 